\title{
Treatment of Pertrochanteric Fracture Femur by Locking Compression Dynamic Hip Screw Plate
}

\author{
Authors \\ Alaa El Banna, Aly Salama, Ahmed Ashour, Walid El Nawawy, Mohamed Aly, \\ Ahmed M. Bassiony Ismail, Bishoy Bessada, Amr Eltorky, Ramy Shehata, \\ Mohamed S. A. A. Hamed \\ Department of Orthopedic surgery and Traumatology, Faculty of Medicine, University of Alexandria
}

\begin{abstract}
Background: Hip fractures in the elderly are common. Intertrochanteric fractures account for nearly 50\% of all fractures of the proximal femur. From 50 to $60 \%$ are classified as unstable. Almost 9 of 10 hip fractures occur in patients older than 65 years and almost 3 of 4 fractures occur in women. It is estimated that one third of all women (and one sixth of all men) reaching the age of 90 years will have sustained at least one hip fracture.

Aim of the Study: The aim of this study is to assess the results of treatment of pertrochanteric fractures by dynamic hip screw locking compression plate.

Patients: This prospective study included 40 patients with trochanteric fractures at El-Hadra University Hospital from September 2015 to December 2016.All cases were fixed by dynamic hip screw locking compression plate.

Subjects and Methods: Evaluation of the clinical and radiological results using Foster Rating System created for the assessment of treatment results in traumatic fractures of the trochanteric region of the femur after a period of 6 months.

Results: At the end of the follow-up period, , twenty three patients had excellent results (57.5\%), nine patients had good results (22.5\%), five patients had fair results (12.5\%) and three patients had poor results (7.5\%) according to Foster functional grading.

According to Foster anatomical grading, Twenty three patients had excellent results (57.5\%), eleven patients had good results (27.5\%), four patients had fair results (10\%) and two patients had poor results(5\%).

Conclusion: A locking compression DHS provides a biomechanically stable construct, with minimal incidence of implant-related failures in treatment of pertrochanteric fractures.
\end{abstract}

\section{Introduction}

Hip fractures are the second most common cause of hospitalization for elderly patients. $^{(1)}$ Trochanteric fracture is common in elderly population. Ninety percent of trochanteric fractures in the elderly patients result from a simple fall and is a considerable burden to the health care system through their association with increased mortality and morbidity. ${ }^{(2,3)}$

The goal of treating hip fracture is to return patients to their prefracture level of function without long-term disability and avoiding medical complications. $^{(4)}$

Although many devices can achieve rigid fixation, the dynamic hip screw (DHS) is the most commonly used device for trochanteric fractures. ${ }^{(5-7)}$ Despite being a highly successful device, it has a rate of mechanical failure, which has been reported between $16-23 \% .^{\left({ }^{(8)}\right.}$ 


\section{Patients and Methods}

This prospective study included 40 patients with trochanteric fractures at El-Hadra University Hospital from September 2015 to December 2016. All cases were fixed by dynamic hip screw locking compression plate.

The age of the patients ranged from $53-84$ years with the mean value of 68.47 years $( \pm$ SD 7.72). All patients were assessed clinically as regarding personal history, history of the trauma, and clinical examination of the lower limbs regarding the presence of a deformity, swelling, skin condition, pain and tenderness, numbness. Radiological assessment included plain X-ray views (AP \& Lateral) of both hips.

Surgical Technique: General or spinal anesthesia is administered as required. The patient is positioned supine on the fracture table. C-arm image intensifier control during surgery is a must. Closed reduction can usually be obtained with gentle traction and internal rotation of the fractured leg. The reduction must be checked in both the AP and lateral view with an image intensifier. The first step is to position a guide wire on the neck and hammer it into the head. Insert the guide wire centrally in head femur in subchondral bone. Determine the length of the DHS screw with the help of the measuring device. Select a screw which is $10 \mathrm{~mm}$ shorter than the measured length, drill a hole for the screw and tapping to insert lag screw. Then insert locking compression DHS plate.

Early active exercise of the knee and quadriceps exercise were explained to the patient from the second postoperative day and encouraged as tolerated by the patient.

Partial weight bearing with toe touch technique were allowed according to the stability of fixation. The patients were subjected to regular visits every 6 weeks for at least 6 months. At the end of follow up, all patients were examined clinically and radiologically and evaluated according to the Foster Rating System created for the assessment of treatment results in traumatic fractures of the trochanteric region of the femur.

\section{Results}

At the end of the follow-up period, , twenty three patients had excellent results $(57.5 \%)$, nine patients had good results $(22.5 \%)$, five patients had fair results $(12.5 \%)$ and three patients had poor results (7.5\%) according to Foster functional grading.

According to Foster anatomical grading, Twenty three patients had excellent results $(57.5 \%)$, eleven patients had good results $(27.5 \%)$, four patients had fair results (10\%) and two patients had poor results $(5 \%)$.

There were two patients (5\%) got infected, one patient $(2.5 \%)$ with superficial infection who was treated by daily dressing and appropriate antibiotic. The other one was uncontrolled diabetic and had deep infection that required serial debridement and vacium seal sessions ending with removal of the plate.

Failure of fixation occurred in two patients $(5 \%)$. In one patient $(2.5 \%)$, failure was attributed to cut out of the lag screw at the postero-lateral edge of the femoral head that occurred within four months. In one patient (2.5\%) failure was caused by penetration of the lag screw into acetabulum that occurred within three and half months. There was no pulling out of the plate from the femur in any case.

\section{Discussion}

Although many internal fixation devices provide sufficient stabilization, the surgical treatment of intertrochanteric femoral fractures is still challenging ${ }^{(9)}$. The dynamic hip screw, which provides rigid fixation and allows early mobilization because it enables optimal collapse and compression of the fracture site ${ }^{(10)}$, is the most common extramedullary device used for intertrochanteric fractures and has reasonable results $^{(11-13)}$. In addition, when compared with sliding hip screws, no evidence exists of a reduced failure rate with intramedullary nails in unstable intertrochanteric fractures ${ }^{(14)}$.

Locking plates increase the strength of DHS and would reduce the risk of DHS failure. ${ }^{(15)}$ A 
locking compression DHS would be particularly useful in patients with osteoporotic bone, and in patients with less stable fracture configurations. ${ }^{(16)}$ Fourty patients were included in this study with trochanteric fracture. All cases were operated and fixed by locking compression dynamic hip screw (LCP DHS). The age of the patients ranged from 53 -84 years with the mean value of 68.47 years $( \pm$ SD 7.72$)$. There was no statistically significant relation between patients 'age and the final results $(p=0.663 \& p=0.493)$. These results are similar to the results of Davis, et al. ${ }^{(17)}$ (1990) found out that $98 \%$ of the patients in whom the fixation failed were $\leq 60$ years old and $2 \%$ were $>60$ years old. These results were statistically insignificant $(\mathrm{p}=$ $0.326){ }^{(17)}$

In this study, the sex distribution was 27 males $(67.5 \%)$ and 13 females $(32.5 \%)$. In the failure group (functional results) the females were $33.7 \%$ and the males were $66.7 \%$. The results were statistically insignificant in functional results $(\mathrm{p}=$ $0.297)$ and in radiological results $(\mathrm{p}=0.327)$. These results are similar to the results of Davis, et al. ${ }^{(17)}$ who found out that the sex of the patients had no effect on the rate of fixation failure, in the failure group the females were $(47 \%)$ and the males were $(53 \%)$, and in the union group the females were $(39 \%)$ and the males were $(61 \%)$. The results were statistically insignificant $(\mathrm{p}=0.204){ }^{(17)}$

In this study, the unsatisfactory results (poor and fair) was concentrated in Evan's type III and IV. The results were statistically significant in functional results $(p=0.025)$ and in radiological results $(p=0.001)$. This matches the results of Weon-Yoo Kim et $\mathrm{al}^{(18)}$ (2001), according to Evans' classification, there were two failed fractures among 48 in type I and type II which are stable fractures, and seven of 28 in type III (26\%), nine of 37 in type IV (24\%), and 31 of 66 in type V (47\%) which are all unstable fractures. These results reveal a significant correlation between failure and stable/unstable fractures. ${ }^{(18)}$

Regarding the effect of osteoporosis on the results in this study in three patients with poor functional results, two patients $(66.7 \%)$ had grade III Singh index and one patient (33.3\%) had grade II Singh index. In five patients with fair functional results, three patients $(60 \%)$ had grade III Singh index, one patient $(20 \%)$ had grade II Singh index and one patient $(20 \%)$ had grade I Singh index. The results were statistically insignificant in functional $(\mathrm{p}=0.234)$ and radiological grading $(\mathrm{p}=0.243)$. This does not match the results of Weon-Yoo Kim et al ${ }^{(18)}$ (2001), according to Singh Index Grade, there were 33 failed fractures in 85 osteoporotic patients (grades I, II and III; 39\%), and 16 failed fractures of 93 non-osteoporotic patients (grades IV, V and VI; 17\%). Thus these results reveal a significant relationship between failure and osteoporosis. (18)

Regarding the effect of the medical history of the patients according to American Society of Anesthesiologists (ASA) on the results in this study American Society of Anesthesiologists (ASA) In eight patients in whom unsatisfactory functional results (poor, fair) occured, three patients $(37.5 \%)$ had grade II ASA and five patients $(62.5 \%)$ had grade III ASA. The results were statistically significant in functional results $(\mathrm{p}=0.001)$ and in radiological results $(\mathrm{p}=$ 0.001).This deos not match the results of baumgaertner, et al. ${ }^{(8)}(1995)$ the medical status of the patient hand no significant effect on the results ( $\mathrm{p}=0.60$, multiple contingency analysis) ${ }^{\left({ }^{(8)}\right.}$

\section{Conclusions}

In conclusion, this study demonstrated thatthe locking compression DHS provides a good choice for treatment of pertrochanteric fractures. It provides a biomechanically stable construct, with minimal incidence of implant-related failures and would be particularly useful in patients with osteoporotic bone, and in patients with less stable fracture configurations.

\section{References}

1. Beaupre LA, Jones CA, Saunders LD, Johnson DW, Buckingham J, Majumdar SR. Best practices for elderly hip fractures 
patients: a systemic overview of the evidence. J Gen Intern Med 2005; 20: 1019.

2. Koval JK, Cantu RV. Intertrochanteric fractures. In: Bucholz RW, Heckman JD, Court-Brown CM, (eds). Rockwood and Green fracture in adults. $6^{\text {th }}$ ed. Philadelphia: Lippincott Williams and Wilkins, 2006. 1793-825.

3. Kanis J, Borgstrom F, Delaet C, Johnsson H, Johnell O, Jonsson B, et al. Assessment of fracture risk. Osteoporosis Int 2005; 16: 5819.

4. Iavelle DG. Fractures and dislocations of the hip. In: Canale ST, Beaty JH, (eds). Campbell's operative orthopaedics. $11^{\text {th }} \mathrm{ed}$. Philadelphia: Mosby, 2008. 3237-8.

5. Alobaid A, Harvey EJ, Elder GM, Lander P, Guy P, Reindl R. prospective randomized trial of two techniques of insertion of a standard dynamic fixation device. J Orthop Trauma 2004; 18: 207-12.

6. Bolhofner B, Russo P, Carmen B. Results of intertrochanteric femur fractures treated with a 135-degree sliding screw with a two-hole side plate. J Orthop Trauma 1999; 13: 5-8.

7. Mcloughlin S, Wheeler D, Rider J. Biomechanical evaluation of the dynamic hip screw with two-and four- hole side plates. J Orthop Trauma 2000; 14: 318-23.

8. Baumgaertner MR, Curtin SL, Lindskog DM. The value of tip-apex distance in predicting failure of fixation peritrochantric fractures of hip. J Bone Joint Surg(Am) 1999; 577A:1058-64.

9. Panesar SS, Mirza S, Bharadwaj G, Woolf V, Ravikumar R, Athanasiou T. The percutaneous compression plate versus the dynamic hip screw: a meta-analysis. Acta Orthop Belg 2008; 4(1):38-48.

10. Lee YS, Huang HL, Lo TY, Huang CR. Dynamic hip screw in the treatment of intertrochanteric fractures: a comparison of two fixation methods. Int Orthop 2007; 31(5):683-8.
11. Bolhofner BR, Russo PR, Carmen B. Results of intertrochanteric femur fractures treated with a 135-degree sliding screw with a two hole side plate. J Orthop Trauma 1999; 13(1):5-8.(Repeated with 7)

12. McLoughlin SW, Wheeler DL, Rider J, Bolhofner B. Biomechanical evaluation of the dynamic hip screw with two- and four hole side plates. J Orthop Trauma 2000; 14(5): 318-23.

13. Lyons AR. Clinical outcomes and treatment of hip fractures. Am J Med 1997; 103(2A):51S-63S.

14. Jones HW, Johnston P, Parker M. Are short femoral nails superior to the sliding hip screw? A meta-analysis of 24 studies involving 3,279 fractures. Int Orthop 2006; 30(2): 69-78.

15. Jewell DP, Gheduzzi S, Mitchell MS, Miles AW. Locking plates increase the strength of dynamic hip screws. Injury 2008; 39:209-12.

16. Barwar N, Meena S, Aggarwal SK, Garhwal P. Dynamic hip screw with locking side plate: a viable treatment option for intertrochanteric fracture. Chin J Traumatol 2014; 17:88-92.

17. Davis TRC, Sher JL, Checketts RG, Poter BB. Intertrochanteric fractures of the femur: a prospective study comparing the use of the Kuntscher-Y nail and a sliding hip screw. Injury 1988;19:421-6.

18. Kim WY, Han CH, Park JI, Kim JY. Failure of intertrochanteric fracture fixation with a dynamic hip screw in relation to pre-operative fracture stability and osteoporosis. Int Orthop 2001;25(6):360-2. 